\title{
Strongyloidiasis in a Puppy in Northeastern Brazil
}

\author{
Rodrigo Cruz Alves $\mathrm{iD}$, Yanca Góes dos Santos Soares (iD, Jôvanna Karine Pinheiro \\ João Ricardo Cruz Brito Junior $(\mathbb{D}$, Raquel Annes Fagundes Silva (D), Millena de Oliveira Firmino (D), \\ Glauco José Nogueira de Galiza (iD) \& Antônio Flávio Medeiros Dantas (iD
}

\begin{abstract}
Background: Strongyloides stercoralis is a nematode that causes intestinal infection in vertebrate hosts, especially in humans and dogs. The species $S$. stercoralis is responsible for chronic and asymptomatic infections in adult dogs or serious infections in puppies and immunosuppressed animals. In Brazil, natural infection in dogs was demonstrated by coproparasitological and serological methods, however, there are no reports that address the clinicopathological characteristics of the infection in the canine species. Thus, this paper aims to describe the epidemiological, clinical and pathological aspects of $S$. stercoralis infection in a puppy in Northeastern Brazil.

Case: A puppy female Chihuahua was referred to the Animal Pathology Laboratory of the Veterinary Hospital of the Federal University of Campina Grande for necropsy with a historic of severe respiratory symptoms and gastrointestinal changes that included sanguineous diarrhea and vomiting that evolved to death in 5 days. Grossly, there was a moderate amount of slightly reddish fluid in the thoracic cavity. The lungs remained expanded with a smooth, shiny, and diffusely reddish pleural surface interspersed with multifocal and blackened coalescent areas. Upon cutting, a moderate amount of slightly yellow foamy liquid flowed from the airways and trachea. In the duodenum, the mucosa was diffusely reddened. Histologically, there were multifocal to coalescent areas of moderate interalveolar accumulation of fibrin, edema and hemorrhage in the lung surrounded by an inflammatory infiltrate composed of foamy macrophages associated with numerous parasitic structures in longitudinal and transverse sections in the alveolar lumen and pleural surface. In the duodenum, we observed flattening with diffuse and moderate fusion of the villi and multifocal areas of mucosal erosion. The crypts were moderately dilated, covered by attenuated epithelium, with numerous longitudinal and transversal sections of adult nematode parasites, larvae and eggs associated with inflammatory lymphplasmocytic infiltrate in the lamina propria. The morphological characteristics were compatible with the nematode $S$. stercoralis.

Discussion: The diagnosis of strongyloidiasis was performed by means of microscopic lesions associated with parasitic structures morphologically compatible with the nematode $S$. stercoralis. This species is responsible for parasitism especially in humans, dogs, and cats. Parasites are the only ones that have a life cycle that involve free living form and parasitic. In this case, it was not possible to determine the primary portal of entry for the infection, but most infections commonly occur through the penetration of the larvae into the skin or mucous membranes, where they migrate via the haematogenous to the lung, then they are swallowed up to the intestine. Occasionally, there is autoinfection by larvae that enter the intestinal mucosa or perianal region and the contamination of neonates and puppies through the ingestion of milk. The clinical signs evidenced in this case, revealed the committed respiratory and gastrointestinal, possibly may be related to the migration of the larvae in the lungs and the destruction of the intestinal epithelium caused by the high number of parasites, respectively. It is concluded that strongyloidiasis is an uncommon infectious disease in puppies in Brazil, capable of causing severe respiratory and gastrointestinal changes that result in the death of animals with a high parasitic load and should be included in the differential diagnosis of diseases that affect the respiratory system and gastrointestinal tract of dogs.
\end{abstract}

Keywords: dog disease, parasitic infection, nematode, Strongyloides stercoralis.

DOI: $10.22456 / 1679-9216.113326$ 


\section{INTRODUCTION}

Strongyloides stercoralis is a nematode that causes intestinal infection in vertebrate hosts, especially in humans and dogs [5] from tropical and subtropical areas around the world [15]. The life cycle of this parasite is complex and is characterized by two generations of adults, one parasitic (in the host) and the other free-living [6]. Infections usually result from the larvae penetrating the skin or mucous membranes with haematogenous migration to the lung where they are swallowed and arrive in the intestine [8].

Parasitism by $S$. stercoralis can result in chronic and asymptomatic infections in adult dogs or severe infections in puppies and immunosuppressed animals $[3,6]$. Sporadic cases about the clinical form of strongyloidiasis have been described in several countries in Europe [2-4,11,12], while in some countries in Asia and South America, studies have only revealed the prevalence of the infection $[1,10,14]$.

In Brazil, spontaneous cases of $S$. stercoralis infection in dogs have been identified by coproparasitological and serological methods [5]. However, data on the clinicopathologic features of infection remain scarce. Thus, the objective of this paper is to describe the epidemiological, clinical, and pathological aspects of S. stercoralis infection in a puppy in Patos, PB, Northeastern Brazil.

\section{CASE}

A puppy female Chihuahua was referred to the Animal Pathology Laboratory of the Federal University of Campina Grande (UFCG) for necropsy with a history of bloody diarrhea, vomiting, dyspnea, hypoxia, cyanosis, tiredness, nasal discharge and pulmonary rales with evolution to death in 5 days. The animal was acquired from a kennel within course treatment for pneumonia and there was admitted to a private veterinary clinic.

Grossly, a moderate amount of slightly reddish fluid was observed in the thoracic cavity. The lungs remained expanded with smooth, shiny, and diffusely reddish pleural surface interspersed with black to coalescent multifocal areas, especially in the caudal lobes (Figure 1A). Upon cutting, a moderate amount of slightly yellow foamy liquid flowed from the airways. In the duodenum, the mucosa was diffusely red, covered by a thick and friable material with reddish content (Figure 1B).
Tissue samples were collected from the abdominal and thoracic viscera, as well as the central nervous system. Samples were fixed in $10 \%$ neutral buffered formalin, processed routinely and embedded in paraffin wax. Sections were stained with hematoxylin $^{1}$ and $\operatorname{eosin}^{2}(\mathrm{HE})$.

Microscopically, the lesions were restricted to the lungs and duodenum. In the lung, multifocal to coalescent areas of moderate interalveolar deposition of weakly eosinophilic and amorphous material (edema) were observed and strongly eosinophilic and fibrillar material (fibrin) associated with moderate hemorrhage. These areas were surrounded by inflammatory infiltrate consisting predominantly of foamy macrophages associated with numerous filariform parasitic structures (larval stage) seen in longitudinal and transverse sections in the alveolar lumen and pleural surface (Figure 1C).

In the duodenum, the lesions were characterized by flattening with diffuse and moderate fusion of the villi and multifocal areas of mucosal erosion. The crypts were moderately dilated and covered with flattened epithelium. In the lumen of the crypts was observed numerous adult nematodes in longitudinal and transverse sections (Figure 1D), larvae and eggs. In addition, a moderate mononuclear inflammatory infiltrate composed of lymphocytes and plasmocytes was observed, distending the lamina propria and submucosa.

Adult nematodes were characterized by having eosinophilic smooth cuticle, platimiarian musculature, intestinal and reproductive tracts inside pseudocoelom measuring approximately $40-50 \mu \mathrm{m}$ in diameter. The larvae presented themselves as filarioide structures measuring $50 \mu \mathrm{m}$ in length filled with finely granular basophilic material. The eggs measured approximately $40-50 \mu \mathrm{m}$ in diameter with a thin shell, eosinophilic to magenta, and filled with basophilic dotted material in the middle of the granular eosinophilic matrix. The morphological characteristics of the parasitic structures were compatible with the nematode $S$. stercoralis.

\section{DISCUSSION}

The diagnosis of strongyloidiasis was performed by means of microscopic lesions associated with the characteristics of the parasitic structures present in the mucosa of the small intestine and lung, which are morphologically compatible with $S$. stercoralis. This species is responsible for parasitism, especially in humans, dogs and cats, while the other species infect other 


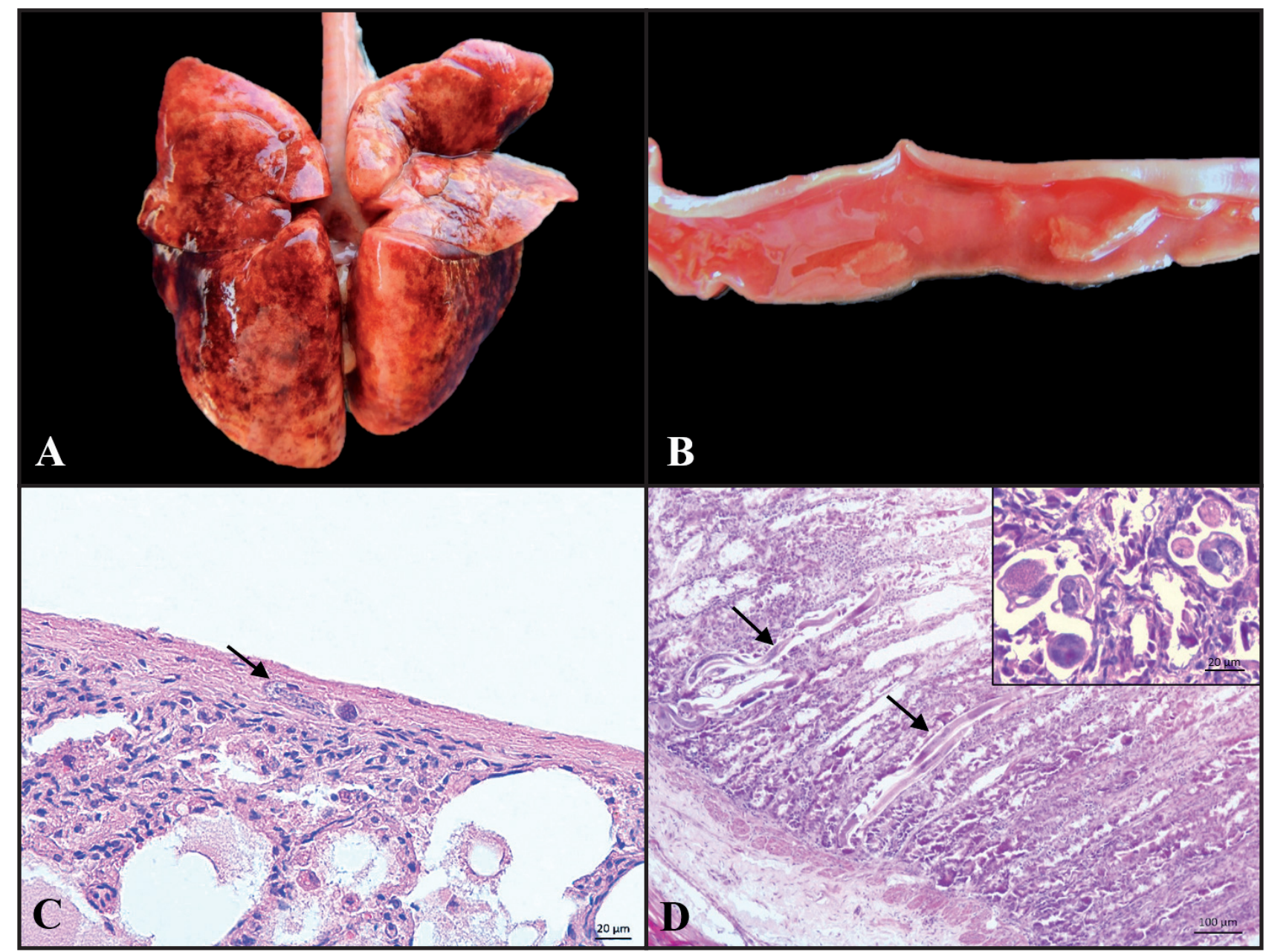

Figure 1. Strongyloidiasis in a dog. A- The lungs remained expanded with smooth, shiny, and diffusely reddish pleural surface interspersed with black to coalescent multifocal areas. B- Duodenum with diffusely reddish mucosa covered by yellowish thick and friable material. C- Lung. Pleural surface with S. stercoralis larva in longitudinal section (arrow) [HE; barra $=20 \mu \mathrm{m}]$. D- Duodenum. Intestinal crypts with multiple specimens of adult nematodes in longitudinal sections (arrows) [HE; barra $=100 \mu \mathrm{m}$ ]. Inset: nematodes in transverse sections inside the crypts [HE; barra $=20 \mu \mathrm{m}$ ]

domestic animals including S. papillosus in ruminants; $S$. westerii in horses; S. ransomi in swine; S. felis, $S$. planiceps $(=S$. catti) and $S$.tumefaciens in cats $[16,17]$.

Strongyloides spp. are the only parasites with a life cycle that involve free-living and parasitic life forms [6]. In the host, only females are parasites with egg production by parthenogenesis in the small intestine [3]. First-stage larvae hatch and are excreted in the feces, developing into third-stage infective larvae or developing through larval stages in free-living adult worms that reproduce sexually in the environment to generate third-stage larvae $[7,16]$. In this case, it was not possible to determine the primary portal of entry for the infection, but most infections commonly occur through the penetration of the larvae into the skin or mucous membranes, where they migrate via the haematogenous to the lung, then they are swallowed up to the intestine $[8,17]$. Occasionally, there is autoinfection by larvae that enter the intestinal mucosa or perianal region and the contamination of neonates and puppies through the ingestion of milk [15].

In adult dogs, infections are often mild and asymptomatic, but neonate animals and puppies may have severe infections that result in acute pneumonia with hemorrhage and diarrhea [3]. The clinical signs evidenced in this case, characterized the respiratory and gastrointestinal impairment, can possibly be related to serious injuries secondary to the larvae migration in the lungs and the destruction of the intestinal epithelium caused by the high number of parasites, respectively. Symptomatic infections that result in the death of dogs, as seen in this case, have not been described in Brazil. However, the prevalence of natural infection by $S$. stercoralis in asymptomatic dogs ranged from $0.9 \%$ in the coproparasitological exam to $20.9 \%$ using serological methods [5]. In the country, similar 
serious infections have been described in humans and eventually resulted in systemic involvement due to immunosuppression $[13,18]$.

Infection with $S$. stercoralis features a worldwide distribution, frequently occurring in tropical and subtropical areas [15], being reported especially in environments with a high density of dogs, such as kennels, where the infection is highly pathogenic and fatal in dogs with a few months old [3], as observed in this case. However, no data were reported on worming, number of animals housed, as well as the sanitary conditions of the site or even the probability of the animals' access to external environments. The control of strongyloidiasis is carried out by sanitizing the facilities and worming the animals [9].

We conclude that strongyloidiasis is an uncommon infectious disease in puppies in Brazil, capable of causing severe respiratory and gastrointestinal changes that result in the death of animals with a high parasitic load and should be included in the differential diagnosis of diseases that affect the respiratory system and gastrointestinal tract of dogs.

\section{MANUFACTURERS}

${ }^{1}$ Erviegas Química Fina e Plásticos Ltda. Indaiatuba, SP, Brazil. ${ }^{2}$ Imbralab Química e Farmacêutica Ltda. Ribeirão Preto, SP, Brazil.

Acknowledgments. The authors are grateful to Coordination for the Improvement of Higher Education Personnel (CAPES) and to the productivity scholarship of the National Council for Scientific and Technological Development $(\mathrm{CNPq})$, process number 309460/2017-4.

Declaration of interest. The authors report no conflicts of interest. The authors alone are responsible for the content and writing of the paper.

\section{REFERENCES}

1 Anselmi M., Buonfrate D., Espinoza AG., Prandi R., Marquez M., Gobbo M., Montresor A., Albonico M., Orbe MR., Moreira J.M. \& Bisoffiet Z. 2015. Mass administration of ivermectin for the elimination of onchocerciasis significantly reduced and maintained low the prevalence of Strongyloides stercoralis in Esmeraldas, Ecuador. PLOS Neglected Tropical Diseases. 9(11): 1-12.

2 Cervone M., Giannelli A., Otranto D. \& Perrucci S. 2016. Strongyloides stercoralis hyperinfection in an immunosuppressed dog from France. Revue Vétérinaire Clinique. 51(2): 55-59.

3 Dillard K.J., Saari S.A. \& Anttila M. 2007. Strongyloides stercoralis infection in Finnish kennel. Acta Veterinaria Scandinavica. 49(37): 1-6.

4 Epe C., Ising-Volmer S. \& Stoye M. 1993. Parasitological fecal studies of equids, dogs, cats, and hedgehogs during the years 1984-1991. Dtsch Tierarztl Wochenschr. 100(11): 426-428.

5 Ferreira Júnior A., Gonçalves-Pires M.R.F., Silva D.A.O., Gonçalves A.L.R. \& Costa-Cruz J.M. 2006. Parasitological and serological diagnosis of Strongyloides stercoralis in domesticated dogs from southeastern Brazil. Veterinary Parasitology. 136(2): 137-145.

6 Gelberg H.B. 2017. Alimentary System and the Peritoneum, Omentum, Mesentery, and Peritoneal Cavity. In: Zachary J.F. (Ed). Pathologic Basis of Veterinary Disease. 6th edn. St. Louis: Elsevier, pp.324-411.

7 Graham J.A., Sato M., Moore A.R., McGrew A.K., Ballweber L.R., Byas A.D., Kristy L. \& Dowers K.L. 2019. Disseminated Strongyloides stercoralis infection in a dog following long-term treatment with budesonide. American Veterinary Medical Association. 254(8): 974-978.

8 Grove D.I. 1996. Human strongyloidiasis. Advances in Parasitology. 38: 251-309.

9 Itoh N., Kanai K., Hori Y., Nakao R., Hoshi F. \& Higuchi S. 2009. Fenbendazole treatment of dogs with naturally acquired Strongyloides stercoralis infection. Veterinary Record. 164(18): 559-560.

10 Martins C.M., Barros C.C., Bier D., Marinho A.P., Figueiredo J.M., Hoffmann J.L., Molento M.B. \& Biondo A.W. 2012. Dog parasite incidence and risk factors, from sampling after one-year interval, in Pinhais, Brazil. Revista Brasileira de Parasitologia Veterinária. 21(2): 101-106.

11 Papazahariadou M., Founta A., Papadopoulos E., Chliounakis S., Antoniadou-Sotiriadou K. \& Theodorides Y. 2007. Gastrointestinal parasites of shepherd and hunting dogs in the Serres Prefecture, northern Greece. Veterinary Parasitology. 148(2): 170-173. 
12 Paradies P., Iarussi F., Sasanelli M., Capogna A., Lia R.P., Zucca D., Greco B., Cantacessi C. \& Otranto D. 2017. Occurrence of strongyloidiasis in privately owned and sheltered dogs: Clinical presentation and treatment outcome. Parasites \& Vectors. 10(1): 1-9.

13 Ribeiro L.C., Rodrigues Junior E.N.A., Silva M.D., Takiuchi A. \& Fontes C.J.F. 2005. Púrpura em paciente com estrongiloidíase disseminada. Revista da Sociedade Brasileira de Medicina Tropical. 38(3): 255-257.

14 Schär F., Inpankaew T., Traub R.J., Khieu V., Dalsgaard A., Chimnoi W., Chhoun C., Sok D., Marti H., Muth S. \& Odermatt P. 2014. The prevalence and diversity of intestinal parasitic infections in humans and domestic animals in a rural Cambodian village. Parasitology International. 63(4): 597-603.

15 Shoop W.L., Michael B.F., Eary C.H. \& Haines H.W. 2002. Transmammary transmission of Strongyloides stercoralis in dogs. Journal of Parasitology. 88(3): 536-539.

16 Thamsborg S.M., Ketzis J., Horii Y. \& Matthews J.B. 2017. Strongyloides spp. infections of veterinary importance. Parasitology. 144(3): 274-284.

17 Uzal F.A., Plattner B.L. \& Hostetter J.M. 2016. Alimentary System. In: Maxie M.G. (Ed). Jubb, Kennedy, and Palmer's Pathology of Domestic Animals. v.2. 6th edn. Philadelphia: Elsevier Saunders, pp.1-257.

18 Veloso M.G.P., Porto A.S. \& Moraes M. 2008. Hiperinfecção por Strongyloides stercoralis: relato de caso autopsiado. Revista da Sociedade Brasileira de Medicina Tropical. 41(4): 413-415. 